\title{
Should relatives be allowed in the resuscitation room?
}

\author{
M H Mitchell, M B Lynch
}

\begin{abstract}
Objective-To assess doctors' and nurses' views on the presence of relatives in the resuscitation room during cardiac arrest or major trauma.

Design-Questionnaires were sent to accident and emergency (A\&E) nurses and doctors of all disciplines in a London teaching hospital. Recipients were asked if they would favour the presence of selected relatives in the resuscitation room and to give comments.

Results-103 questionnaires were distributed and 81 returned, a response rate of $78.6 \% ; 33 \%$ were senior house officers, $29 \%$ consultants, $16 \%$ senior registrars/ registrars, $12 \%$ A\&E nurses, and $10 \%$ house officers. Of the respondents, $63 \%$ were not in favour of relatives being present, and $37 \%$ were in favour. The likelihood of being in favour of allowing relatives to be present was high among A\&E nurses; among doctors it increased with rising seniority. Most respondents felt that more resuscitation training would be necessary, in addition to counselling for staff and relatives.
\end{abstract}

Conclusions-Staff with the least experience in dealing with resuscitations and distressed relatives were likely to be opposed to relatives being present in the resuscitation room. As there is evidence that the bereavement process is eased if a partner/relative witnesses the resuscitation, relatives should be offered the opportunity to witness resuscitation if staff training is geared towards the presence of relatives. ALS/ATLS training for all hospital doctors and nurses should include the management of distressed relatives observing a resuscitation.

(f Accid Emerg Med 1997;14:366-369)

Keywords: resuscitation; relatives

Accident and

Emergency

Department, Queen

Mary's University

Hospital, London

SW15, UK

M H Mitchell

M B Lynch

Correspondence to: Dr Michael H Mitchell, 19 Mill Place,

Kingston-upon-Thames, Surrey KT 12 RS, UK.

Accepted for publication 12 August 1997

Anecdotal evidence suggests that most accident and emergency (A\&E) departments adopt the view that relatives should not, in general, be present in the resuscitation room during cardiorespiratory arrest or major trauma.

There is, however, evidence in both the popular press and medical reports to suggest that partners and those close to the patient would have liked to be present at the resuscitation had they been given the opportunity. A study by Doyle $e^{~}$ al $^{1}$ in 1987 revealed that $72 \%$ of relatives would have chosen to be present if given the choice. In $1992 \mathrm{Kelly}^{2}$ stated that "Relatives of children are not asked to leave the resuscitation room as they have more right than staff to be present at the attempted resuscitation."

Cardiac arrests and major trauma in public places are witnessed by onlookers as a result of circumstance. Whitlock ${ }^{3}$ describes the attempted resuscitation of a horse rider during the three day international event at Windsor in 1995. Sarah Adams, sister of the riding victim Richard Adams, gives a moving account describing the benefits of her presence at the resuscitation of her brother in dealing with her bereavement.

In a 10 year study by Hanson and Strawser ${ }^{4}$ in which relatives were given the option of witnessing resuscitation attempts, family members reported that in those cases where the patient died, the presence of relatives brought a sense of reality to their loss, helping to avoid a prolonged period of denial. We were impressed by the research and were keen to put into practice the policy of offering relatives or loved ones the opportunity of being present in the resuscitation room. Before bringing about a change in practice we decided to assess doctors' and nurses' views so that potential problems could be addressed.

\section{Methods}

Questionnaires were sent to $A \& E$ nurses and doctors of all specialties in all grades of seniority at Queen Mary's University Hospital, Roehampton, in November 1995 (we did not include nurses outside $A \& E$, as changes in our policy would not affect them but would affect doctors in all specialties). One hundred and three questionnaires were sent on a named basis. Recipients were asked to state whether they would or would not favour the presence of relatives in the resuscitation room if the relative had expressed a desire to be there. They were also invited to give comments to support their view. The information gained was analysed. The questionnaire is shown in appendix 1 .

\section{Results}

Eighty one questionnaires were returned, a response rate of $78.6 \%$. A pattern emerged showing that $A \& E$ nurses were likely to be in favour of the presence of relatives, while doctors were more likely to be in favour with increasing seniority $(\mathrm{P}<0.001)$.

STATUS OF RESPONDENTS

House officers formed the smallest proportion $(10 \%)$ of respondents, as they are only attached to medical and surgical firms. A\&E nurses formed $12 \%$ of respondents, registrars $16 \%$, senior house officers $33 \%$, and consultants $29 \%$ (fig 1 ). 


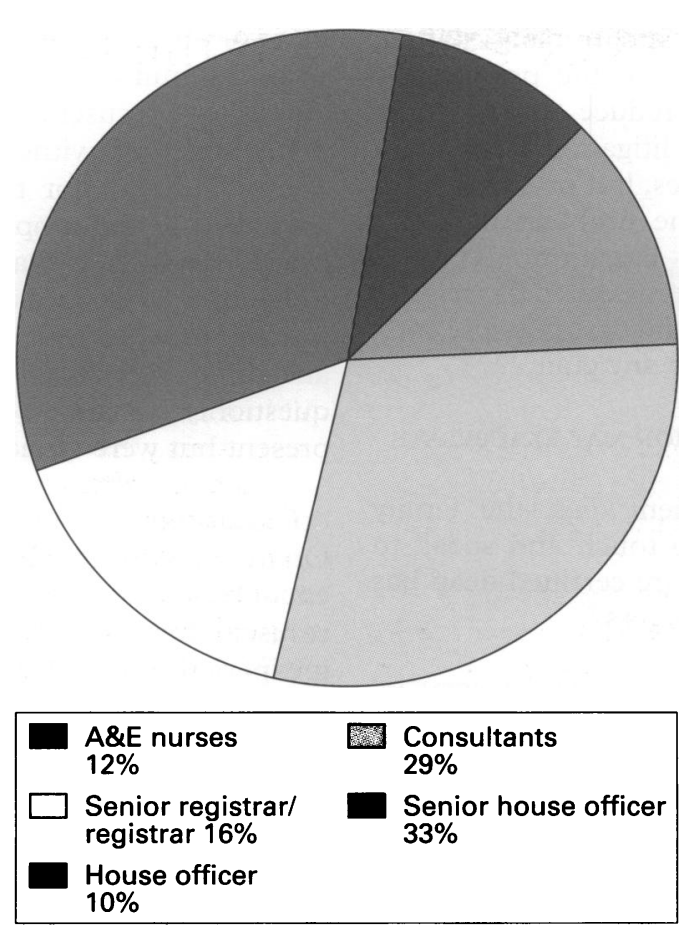

Figure 1 Composition of respondents.

Sixty three per cent of respondents stated that they would not favour the presence of relatives in the resuscitation room (fig 2). The correlation between views on the subject and status is seen in fig 3 . This pattern suggests that the likelihood of being in favour of allowing relatives to witness resuscitation increases with experience, confidence, and competence at dealing with resuscitation techniques and distressed relatives.

Reasons for opposing the presence of relatives at a resuscitation included the following:

(1) Relatives will impede resuscitation (79\% of responders)

(2) Insensitive comments may be made by staff $(43 \%)$

(3) Litigation may increase (20\%)

(4) Witnessing a resuscitation may exacerbate the grieving process $(3 \%)$

(5) The resuscitation procedure may be seen as chaotic $(49 \%)$

(6) Abandoning resuscitation will become difficult $(68 \%)$

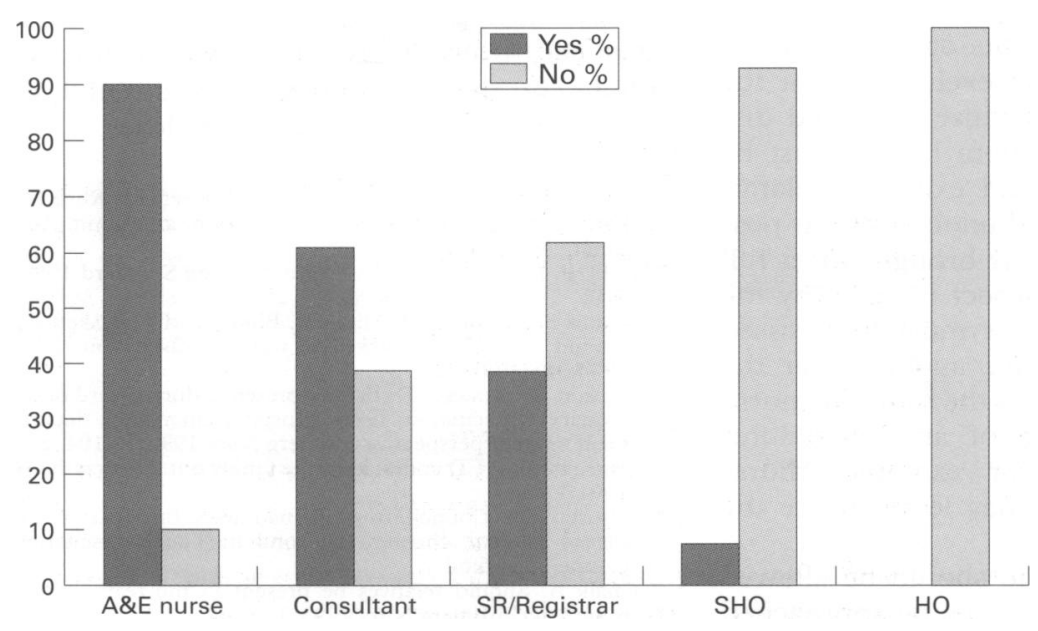

Figure 3 Correlation between views on the presence of relatives at resuscitation and status.

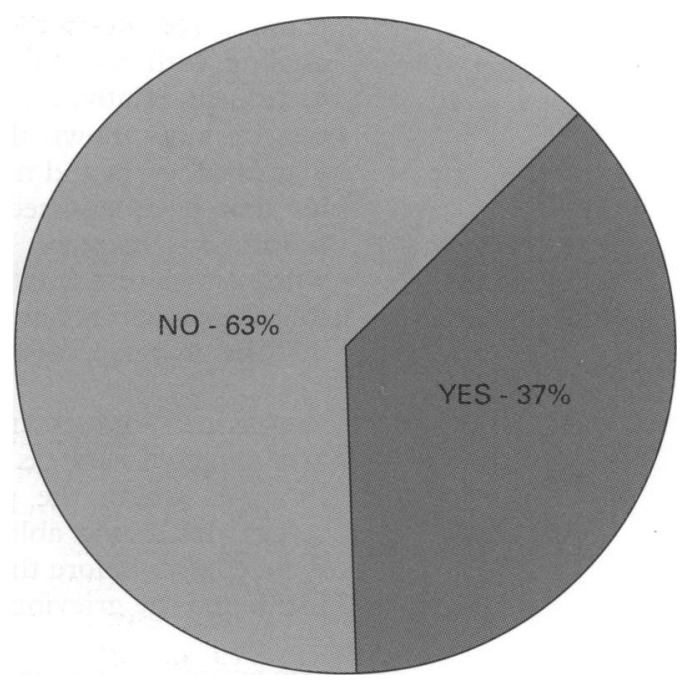

Figure 2 Should relatives be present?

(7) The team may be intimidated by relatives (70\%)

(8) Relatives will be distressed by the resuscitation $(86 \%)$.

Comments in favour of allowing relatives to be present included:

(1) Relatives wishes must be respected (12\%)

(2) The grieving process would be facilitated (5\%)

(3) Relatives would see that everything possible had been done (25\%).

Most respondents felt that more resuscitation training would be necessary, in addition to counselling for staff and relatives.

\section{Discussion}

We feel that the view that no relative should be allowed to witness resuscitation is out of date. The presence of a relative, if handled sensitively and with appropriate staff training ${ }^{7}$ (see below) has been shown to have a positive effect on the bereavement process. We must therefore make appropriate changes within our departments to facilitate the presence of relatives during resuscitation if they choose to attend. It is important, therefore, to address the objections raised above.

RELATIVES WILL IMPEDE RESUSCITATION

The patient must always remain our priority. The relative should be accompanied by an appropriately trained nurse at all times to explain what is happening and to advise the relative to leave in the interests of the patient if they become obstructive.

INSENSITIVE COMMENTS MAY BE MADE BY STAFF Improved advanced life support (ALS) and advanced trauma life support (ATLS) training with an emphasis on dealing with a resuscitation in the presence of a relative should minimise this problem. As doctors and nurses get used to the experience of being watched, their behaviour will adapt accordingly. This has been our experience in our teaching sessions.

\section{LITIGATION MAY INCREASE}

Litigation usually arises from mistrust, misunderstanding, and misinformation. Good 
training for all medical and nursing staff in dealing with resuscitation in the presence of distressed relatives will reduce errors. Most reports have shown that litigation has been a fear for doctors and nurses, but previous studies that have assessed the problem have not found an increase in litigation. ${ }^{5}$ Perhaps witnessing a resuscitation reassures the relative that the patient received the best possible care, and this may help assuage any guilt.

WITNESSING A RESUSCITATION MAY EXACERBATE THE GRIEVING PROCESS

In cases where the patient dies, the family report that being able to touch and speak to their relative before they are certified dead has facilitated the grieving process. ${ }^{6}$

THE RESUSCITATION PROCEDURE MAY BE SEEN AS CHAOTIC

Clear explanation and guidance from a trained nurse will improve the relative's understanding of the witnessed procedures. A well trained resuscitation team should appear competent and chaos-free.

\section{ABANDONING RESUSCITATION WILL BECOME} DIFFICULT

Ending the resuscitation must always be a medical decision. Advanced life support courses now include training on when to end a resuscitation and how to explain the decision to relatives as well as how to break bad news.

THE TEAM MAY BE INTIMIDATED BY RELATIVES

With regular resuscitation training and increased experience of dealing with distressed relatives this problem will diminish. Once it became accepted that in a hospital's accident and emergency department it is routine practice for relatives to be present, the attitude should become more accommodating towards them, especially when a commitment to training and support are seen.

RELATIVES WILL BE DISTRESSED BY THE RESUSCITATION

This is bound to happen, but is not in itself a reason to prevent a relative from witnessing the last moments of their closest relative's life. The relative, by the time they have arrived in hospital, will probably have already witnessed the initial resuscitation attempts at home and in the ambulance and being excluded from the procedures may possibly cause increased distress. The resuscitation room layout must be such that the entrance and exit of a relative must be as convenient and unobtrusive as possible. Before the relative is brought in, a full explanation of what to expect is made by the accompanying nurse and it must be stressed that the relative may leave and re-enter the room if they wish. ${ }^{7}$ When in the room the nurse would warn the relative of any procedures involving blood loss (for example, thoracotomy), so the relative may leave before the procedure if they so wish.

The question as to who should be allowed into the resuscitation room can be approached in two ways: either selected relatives-those who the nurse feels would be unlikely to disturb the resuscitation-would be given the opportunity of witnessing the procedure, or one would wait for the relative to ask to be present. The latter option, we feel, is inappropriate, as it is likely that most relatives would be too intimidated to ask to be present. A tiny fraction of relatives ever asks to be present, but anecdotal reports suggest that, when later questioned, many would have liked to be present but were afraid to ask.

\section{CONCLUSIONS}

On initial questioning, most doctors would not encourage the presence of relatives in a resuscitation. This appears to be related to inexperience and lack of confidence in the traumatic situation. Having assessed the concerns of medical and nursing staff regarding the presence of relatives in the resuscitation room, we are presently implementing the following recommendations:

(1) All hospital medical and nursing staff will receive weekly ATLS/ALS training with emphasis on conduct while being observed and on managing distressed relatives. This has started and the inclusion of role play in the moulage scenarios has been very positively received.

(2) All E grade nurses and above are receiving tuition in explaining resuscitation procedures and comforting distressed relatives.

(3) The resuscitation team should be in agreement that a relative should be present.

(4) The relative should have an allocated space in the resuscitation room, close to an exit.

(5) A pilot study should be performed to monitor the progress and any problems of this approach to resuscitation.

Our protocol for the situation is shown below (appendix 2). There is stress on offering the opportunity to be present rather than waiting to be asked if the loved one may be present. Doubtless people are now more sophisticated and knowledgeable about resuscitation, with TV programmes such as "Casualty" and "ER", and they have an idea of what they may expect to see. Though our primary responsibility is to the patient, we also have a responsibility to potentially bereaved relatives. The way forward is to increase the public's trust in our profession. When we are able to show that we have nothing to hide and that we appreciate the strength of family bonds we shall be one step closer.

1 Doyle CJ, Post H, Burney RE, Maino J, Keefe M, Rhee KJ. Family participation during resuscitation: an option. Ann Fmerg Med 1987;16:673-5

2 Kelly E. Encouraging shared care. Nursing Standard 1992; Kelly $\mathrm{E}$.

3 Adams S, Whitlock M, Higgs R, Bloomfield P, Baskett PJ. Should relatives be allowed to watch resuscitation? $\mathrm{BMJ}$ 1994;308:1687-92.

4 Hanson C, Strawser D. Family presence during cardiopulmonary resuscitation: Foote Hospital emergency department's 9 year perspective. J Emerg Nurs 1992;18:104-6.

5 Osuagwu CC. ED codes: keep the family out. J Emerg Nurs 1991;17:363.

6 Resuscitation Council. Breaking bad news. In: Advanced life support manual, chapter 15. London: The Resuscitation Council, 1996:62.

7 Chalk A. Should relatives be present in the resuscitation room? Accid Emerg Nurs 1995;3:58-61. 


\section{Appendix 1}

Dear Colleague

I would like to know your opinion regarding relatives being present in the resuscitation room during the resuscitation of patients with life threatening conditions. Evidence in the literature suggests that should the patient die, the bereavement process may be facilitated if the relative is present during the resuscitation.

There are occasions when a relative would like to be present during the resuscitation and we feel that relatives' feelings should be respected at such a time. For this reason we are considering making a departmental policy stating that if a relative wishes to be present, they may do so and a senior nurse will accompany them, explaining the procedure and comforting them throughout.

Please complete the form below and return it to me in A\&E.

Yours sincerely

Dr M H Mitchell MRCP, FFAEM

Consultant in Accident and Emergency Medicine

\section{Name}

I would/would not favour the presence of relatives in the resuscitation room in $A \& E$.

Comments:

\section{Appendix 2}

\section{Procedure for the Management of Relatives in the Resuscitation Room}

From Wednesday 12th March, relatives will be offered the opportunity of being present in the resuscitation room during resuscitation. The procedure will be as follows.

1. On arrival the relative will be taken to the relatives' room with a specified nurse and the usual details will be taken.

2. The nurse will then explain to the relative that he/she is going to find out how the patient is faring and once in the resuscitation room the nurse, apart from obtaining clinical details of the patient, will find out from the team if there is any objection to the relative being present, should they so wish.

3. If the team agree to the presence of the relative, the nurse will offer the opportunity to the relative as long as it is felt by the nurse the relative is unlikely to disturb the proceedings. If the team does not agree, the relative will not be offered the opportunity.

4. Before entering the room the nurse will prepare the relative for what they are about to see and the relative will be constantly reassured that they may leave and/or re-enter the room at any time. Once in the resuscitation room (at all times accompanied by the same nurse) the relatives will be permitted to watch the resuscitation with constant reassurance and explanation from the nurse.

5. At such time when the team leader feels it is appropriate to abandon resuscitation the usual team agreement will be obtained, then the team leader will approach the relative to inform them that the patient has died. It is important to convey the news this way so there should be no doubt about why the resuscitation has ended. Monitors will be switched off as the team leader approaches the relative.

Dr M H Mitchell MRCP, FFAEM

Consultant in Accident and Emergency Medicine 